\title{
LONGITUDINAL EVALUATION OF EXECUTIVE FUNCTIONS IN PATIENTS WITH CHILDHOOD-ONSET
} SYSTEMIC LUPUS ERYTHEMATOSUS

Jaqueline Cristina de Amorim (Faculdade de Ciências Médicas - UNICAMP , Campinas, SP, Brasil), Cibele Longobardi Cutinhola Elorza (Faculdade de Ciências Médicas - UNICAMP, Campinas, SP, Brasil), Paula Teixeira Fernandes (Faculdade de Educação Física - UNICAMP, Campinas, SP, Brasil), Bruna Bellini (Faculdade de Ciências Médicas - UNICAMP , Campinas, SP, Brasil), Roberto Marini (Faculdade de Ciências Médicas - UNICAMP , Campinas, SP, Brasil), Simone Appenzeller (Faculdade de Ciências Médicas - UNICAMP , Campinas, SP, Brasil)

\section{BACKGROUND}

Among the neuropsychiatric manifestations of Childhood-onset Systemic Lupus Erythematosus, cognitive losses are frequent. Therefore, the objective of this study was to analyze the fluctuation of executive functions these patients in treatment at a tertiary hospital rheumatology outpatient clinic.

\section{MATERIALS AND METHODS}

This is a longitudinal study with application of validated instruments: Coding subtest, Picture Arrangement , Block Design, Vocabulary and Picture Completion in patients with confirmed diagnosis of Childhoodonset SLE . In this study 24 patients were included, with a mean of 16.83 years, of whom 23 were women and 1 were man. The subjects were evaluated in two different periods with mean separation time of 9.5 months.

\section{RESULTS}

The Coding subtest showed the largest difference between the scoring means, with the first being 58.83 \pm 15.18 (mean \pm SD) and the second $55.20 \pm 20.63$, followed by the arrangement of figures, with $22.87 \pm$ 12.69 and $20.5 \pm 8.88$, and Block Design with $42.37 \pm 13.73$ and $41.62 \pm 13.66$. On the other hand, when analyzing the substandard Vocabulary and Picture Completion, there is an increase in the mean between evaluations, the first one being from $26 \pm 3.21$ to $26.41 \pm 6.48$, and the second from $22.79 \pm 3.28$ to 23.95 \pm 9.03 . When performed the T-test for paired samples, with a $95 \%$ confidence interval, it was not possible to prove the statistical significance when comparing the data obtained in the two evaluations. The Block Design subtest was closest to significance, with a result of 0.328 , followed by Coding with 0.524 .

\section{CONCLUSION}

Although the data analyzed do not have statistical significance it's possible to realize a tendency in the decrease of the ability to perform tasks. In this way, the study provides an indication of impairment in spatial visualization capabilities, selective and focused attention, and mental flexibility and perceptual and visual organization. Further studies are needed to better evaluate the long-term impairment of executive functions on patients with Childhood-onset SLE 